The bottle neck in building a practical natural. language processing system is not those problems which have been often discussed in research papers, but in handling much more dirty, exceptional (for theoretictans, but we frequently encounter) expressions. This panel will focus on the problem which has been rarely written but has been argued informally among researchers who have tried to bulld a practical natural language processing system at least once.

Theory is important and valuable for the explanation and understanding, but is essentially the first order approximation of a target object. As for language, current theories are just for the basic part of the language structure. Real. language usage is quite different from the bastc language structure and a supposed mechanism of interpretation. Natural language processing system must cover real language usage as much as possible. The system model must be designed in such a way that it is clearly understandable by the support of a powerful 1inguistic theory, and stil1 can accept varfeties of exceptional 1inguistic phenomena which the theory is difficult to treat. How we can design such a system is a major problem in natural language processIng, especially for machine translation between the languages of different 1inguistic families. We have to be concerned with both linguistic and non-linguistic world. While we have to study these difficult problems, we must not forget about the realizability of a useful system from the standpoint of engineering.

I received valuable comments from $\mathrm{Dr}$. Karen Jensen who cannot participate in our pane1, and kindly offered me to use her comments freely in our pane1. I want to cite her comments in the followings.

\title{
Why Computational Grammarians Can Be Skeptical About Existing Linguistic Theories
}

\section{Karen Jensen \\ IBM TJ Watson Research Center Yorktown Heights, NY10598, U.S.A}

1. We need to deal with huge amounts of data (number of sentences, paragraphs, etc.). Existing linguistic theories (LTs) play with small amounts of data.

2. The data involve many (and messy) detafls. LTs are prematurely fond of simplicity. For example: punctuation is very important for processing real text, but LTs have nothing to say about it. (This is actually strange, since punctuation represents -- to some extent -- Intonational contours, and these are certainly lingulstically significant.)

3. There is no accepted criterion for when to abandon an LT; one can always modify theory to fit counterexamples. We have fairly clear criteria: if a computational system cannot do its job in real time, then it fails.

4. We need to use complex attribute-value structures, which cannot be manipulated on paper or on a blackboard. "Trees" are on1y superfictally involved. This means we are absolutely committed to computation. LTs have various degrees of commitment.

Existing linguistic theories are of limited usefulness to broad-coverage, real-world computational grammars, perhaps largely because existing theotists focus on limited notions of "grammaticality," rather than on the goal of dealing, in some fashion, will any piece of input text. Therefore, existing theories play the game of ruling out many strings of a language, rather than the game of trying to assign plausible structures to all strings. We suggest that the proper goal of a working computational grammar is not to accept or reject strings, but to assign the most reasonable structure to every input string, and to comment on it, when necessary. (This goal does not seem to be psychologically implausible for human beings, either.)

For years it has seemed theoretically sound to assume that the proper business of a grammar is to describe all of the grammatical structures of its language, and only those structures that are grammatical:

The grammar of $L$ will thus be a device that generates all of the grammatical sequences of $L$ and none of the ungrammatical ones. (Chomsky 1957, p. 13)
5. We are not interested in using the most constrained/ restricted formaltsm. LTs generally are, because of supposed claims about language processing mechanisms.

6. We are interested in uniqueness as much as in generality. LTs usually are not.

7. We are more interested in coverage of the gramur than in completeness of the grammar. LTs generally pursue completeness.

8. We alm for "all," but not "only" the grammatical constructions of a natural language. Defining ungrammatical structures is, by and large, a futile task (Alexis Manaster-Ramer, Wlodzlmierz Zadrozny).

9. Existing LTs give at best a high-level specification of the structure of natural language. Writing a computational grammar is 1ike writing a real program given very abstract spees (Nelson Correa).

10. We are not skeptical of theory, jugt of existing theories.

At first blush, it seems unnecessary to conjure up any justification for this claim. Almost by definition, the proper business of a grammar should be grammaticality. However, it has been notoriously difficult to draw a line between "gram. matical" sequences and "ungrammatical" sequences, for any natural luuman language. It may even be provably impossible to define precisely the notion of grammaticality for any language. Nalural language deals with vague predicates, and might itself be called a vague predicator.

This being true, it still seems worthwhile to aim at parsing ALL of the grammatical strings of a language, but parsing ONLY the grammatical strings becomes a dubious enterprise at best. Arguments for doing so neduce either to dogma, or to some general notion of propriety. Arguments against, however. are easy to come by. Leaving theoretical considerations aside for the moment, consider these pragmatic ones:

(a) The diachronic argument. The creativity of human use of language is great, and language systems ate always changing. A construction that was once unacceptable becomes acceptable over time, and vice versa. Even if a grammar could 
Atscribe all and only fie grammatical sequeaces today, the thane way hot be owe tomoriow. So there is, at best, only an anademic interest in only-ganinimaticat structures.

(b) The practical argument. In the area of spplied coro putationat linguistics, ill-formed input is a patt of daily life, and a working brainmar liss to handle it. By "handle it" wo uxean not grond to a hald, but figute our some kind of appro ginte aroulysts atud ther comment, if possible, on whatever is dificut or whisual. If reil-life naturul langunge processing is yoling to erist, theie math be some way to extrut neaning even fhom strings that violate customary syntactic rules, that tre excessively long and coniplex, and that are not sentence 粮: 晋.

At bBin Research, we are developing a broad-coverage yarring grammar for English, called the PL.NLP English Gramina, or PHG, IQs initial synthetic component works only with liatied thionnation - lexical features for parts of speech, for inomphological struciure, and for sorie valency classes. This tomangonut phes to assiggl some reasonable structure to any ingut sing of Englishe.

Even in its curnent beginning state, PEO has proved to

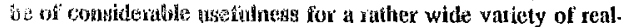

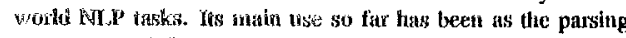
component of CXrTIQUE, a large-scale natural language tex pocesting system that identilies grammar and style etrors in renglishli text (Heiflowit at al. 1982, Richardson and BradenHatei 1988). A probotype CRTTiQUe sysiem is now functioning in thioe major application ateas: business offices, a forblishing center, that univassities.

Real-word natural langunge processing must deal with loge amouns of data, which involve many, and messy, details. for example, gancitution is very linportant in processing real itxl, but curreat linguistic fleories lave nothing substantial (t) say abouf punctuation. Nor have they anylhing subsianbit to say about analysis siruclures for ellipsis, or for strings tiat deviate in various degiees from the canonical order of the language in which they occir. Here is the kind of natural lanEuage input that CRITIQUL has to deal wilh. (All of the text excerpts below are written EXACTLY as they were produced.)

Iisti, a memo that was sent via electronic nual to multiple lsers in the office environment:

(1) Over the course of the next couple of days the accomting depatitnent will conducting inventory of lalss and offices here at $X \times X \times$, I they are currently working on the lisst floor, and working there way up. If you are not in your office fund do not plan to be there within the next few days,plense secure all confidential mail and items you may have of confidential flame. Decause if you are not there accounting is going to go in and intventory your equipment.

The author of text (1) is a hative speaker of American English, who has a college education and is employed in position of some responsibility in a large business firm. Note the following problems:

(a) "will conducting" should the "will conduct";

(b) "coidlucting inveniory" should be "conducting an iiventory";

(c) "I they" should be just "They";

(d) "working thane way up" shuuld be "working their way up";

(c) "days,please" lacks a space between the comma ind "plense";

(1) "of confidential nature" wotyld be betier written as "of a confidential nature";

(g) The lagt text segment is a fragment, not a complefe clause, although it is presented as if it were at sêtititutice.

No lievretically pure grammar wonld ever be able to analyze texi like this. It natay be objected that "granmar" defines the conipetence that makes it possible for us to identify mistakes (a - g), and that any wotking system is an embodiment of a kind of performatice, not conpelence. Very well; note then that the role of "Grainimar" wecontes that of a COMMENTARY on the analysis structune, NOT' the definition of the structure itself. This is exactly the point. It unay be that we need a new delinition of the rem "gratnman."

Within the educational environment, the chatlenge for a computational grimmatis is even stronger. Following are two exceriyts from exsays by non-native English speakexs. Text (2) is an extreme wample of the num-on style of writing; the interesting "grammatical" question is what cues might be used to divide this text into separate sentences:

(2) After the analysis of three graphs we can make conclusion, From 1940 to 1980 the farm population and farms decrease but the average farm size increase, this tendency shows American don't have strong intensie to work on the farms, as a result it is impossible to increase the farms but when The people who would like to work on farms expand their farm size by themselves or the aid of govermment; maybe some other agents want to invest capital in the "farming industry".

Text (3) shows interesting problems with the definite article (mass vs. count NPs) and with auxiliaries in VPs:

(3) So we know, now we can use the fewer people to get the more food. Is the decreasing farmer we deduce on the graph? Is the farms going to decreasing in future? Does the average of farm size will develope? No. No. No.

The problem of non-"grammaticality" is pervasive in real language use. The question

(4) Who did you tell me that won?

supposedly poses an extraclion problem - in terms of Goverument Binding Theory, it violates the Empty Case Principle. Yet it can be heard from the mouths of people who would otherwise qualify as speakers of Staudard English. The sentence

(5) He bought for ten shillings a ring.

supposedly violates an ordering consiraint in English because the prepositional phrase "for ten shillings" precedes the direct object "a ring." However, as the direct object NP becomes heavier and heavier, the sentence sounds better and better:

(5') He bought for ten shillings a ring that delighted the woman who had previously been proposed to by millionaires.

To move "for ten shillings" to a position following the direct object in (5') would be extremely awkward. In this case, it is better to interpret the "grammatical" ordering rule as a stylistic comment. The construction

(6) Himself's father came.

violates theoretical restrictions on anaphora, or Binding; but it is fine if read with an Irish flavor. And the altemative of having a completely separate grammar for Irish English is not appealing. The sentence

(7) Slie be happy.

is censured because the main verb is not tensed; but (7) is valid Non-standard Black English. And so on. Many theoretically proscribed sequences exist and flourish as stylistic or social variants. To ignore them, and to pursue the Holy Grail of a grammar that describes "all and only" the grammatical strings of a language, woukd be to defent the enterprise of broadcoverage computational parsing.

Furthemore, it is not necessary to enforce all of the supposedly "grammatical" restrictions within a computational analysis grammar that actually deals with quantities of real text, in real tinie. Our experience with PEG, in the CRITIQUE application, proves this. PEG produces appropriate parses for (4) - (7). Then a Style component can comment on the parses, calling attention to whatever problems or variations exist. We do not currently handle all of the difficulties posed by (1) (3), but we do handle some of them. For those grammatical restrictions that have to be enforced within the syntactic grammar (such as number agreement), we have a two-pass error detection and correction strategy. For massive problems like the run-ons in (2), we use the technique of the "fitted parse," which tries to identify sensible chunks of text and present then in some reasonable framework.

Since it is neither desirable nor necessary for a computational granimar to define "all and only" the "grammatical" sequences of a language, and since working computational grammars are the most comprehensive descriptions that we can come up with, tight now, for natural languages, we suggest that the goal of renl-world gramnatical analysis be re-defined: a grammar should try to describe "all," but not "only," the grammatical strings of a language. 